\title{
Experimental study of geometrical characteristics of distilled water and aqueous ethanol solution droplets evaporating on aluminum surface
}

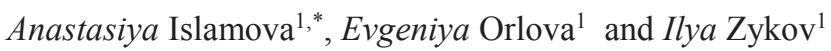 \\ ${ }^{1}$ National Research Tomsk Polytechnic University, Tomsk, Russia
}

\begin{abstract}
Change of geometrical characteristics of distilled water and aqueous ethanol solution droplets was studied under their evaporation on aluminum surface. According to change in the contact diameter three evaporation modes of distilled water droplet on polished aluminum surface were detected: increase in the contact area, pinning of a droplet (constant contact area), and droplet depinning (decrease in the contact diameter). During evaporation of aqueous ethanol solution droplets, two evaporation modes were detected: increase in the contact area, and droplet depinning.
\end{abstract}

\section{Introduction}

The last 20 years the interest for many practical applications has become heat and mass transfer processes in the mini- and microsystems. It is due to the intensive development of microelectronics and medicine, as well as the miniaturization of various kinds of process control and monitoring equipment (aerospace, automobile manufacturing, and transportation field) [1-11]. There is an intensive development of heat exchange systems with micro- and nanoscale. It is known [12-15] that such systems are much more efficient than their analogs with typical dimensions of units and tens of millimeters. For example, in recent years, thermosyphons and heat pipes with the transverse dimensions of 2 millimeters or less are applied for cooling microelectronic equipment [16-17]. But research in this area is being conducted primarily as a search for functional options (using such characteristics of search as refrigerants, materials, regime parameters, size, and configuration items) without analyzing the basic physics of processes occurring in such equipment [18]. Typically, materials for mini heat exchange systems are non-ferrous metals, and the movement of coolant is implemented mainly in the form of rivulet currents, which can disintegrate into separate drops.

To date, theoretical foundations of evaporation of pure liquids and solutions droplets have not been developed to a level that provides a predictive evaluation of the impact of various factors on the physical process.

\footnotetext{
${ }^{*}$ Corresponding author: agi2@,tpu.ru
} 
There is a lack in the experimental data on heat transfer characteristics in the vicinity of the three-phase contact line (gas/liquid/substrate). Most researchers (R. Hoffman, J. Bachelor, T. Blake, V.M. Starov, R.G. Cox et al.) have been studying the process of evaporation of pure liquids. But the study of the contact angle and the contact line of the drop evaporation of solution on a solid substrate is dedicated to small the number of research.

The intensity of the evaporation process, contact diameter, contact angle are known to be affected by many factors, among them the liquid vapor pressure, thermal conductivity, roughness of the substrate, shape of the surface microstructure, composition of the liquid, impurities in liquids and others [18].

Conducting experimental studies using modern recording equipment will clarify the understanding of the mechanisms of evaporation of pure liquids and solutions droplets. It will develop the physical bases for designing energy-efficient heat exchange systems of small dimensions, in which the heat transfer agent moves in rivulet way or forms droplet irrigation.

The purpose of this work is to study experimentally change in the geometric characteristics of $f$ distilled water and aqueous ethanol solution droplets (41\% and $39 \%$ wt.) evaporating on aluminum substrate. The studies were conducted using the aluminum surface due to the extensive use of non-ferrous metal in the manufacture of heat exchangers.

\section{Materials and Methods}

Experimental studies were carried out by using the shadow system equipment [16]. A droplet of a predetermined volume was placed on the surface by the electronic dispenser. Droplet volume was ranged from 10 to $50 \mu \mathrm{L}$ in increments of $10 \mu \mathrm{L}$. The geometrical parameters of the drops were obtained after processing the shadow image snapshots in software Drop Shape Analyses by Tangential 1 method.

Fig. 1 shows the obtained dependences of the droplet contact diameter on time at the initial substrate temperature of $\mathrm{t}=60^{\circ} \mathrm{C}$.

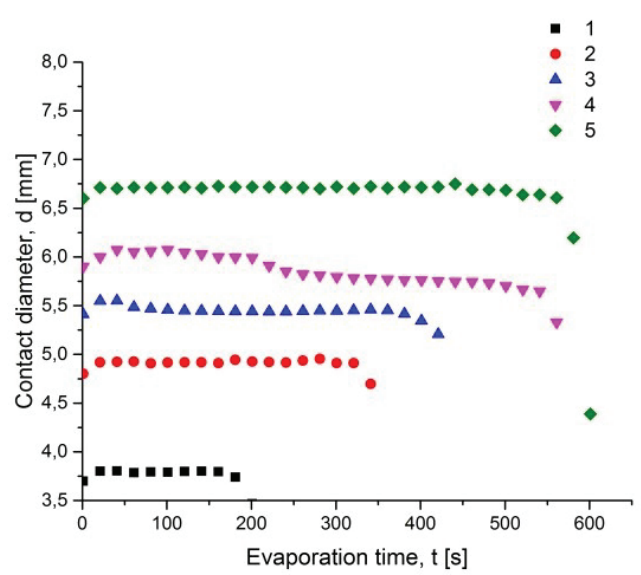

(a)

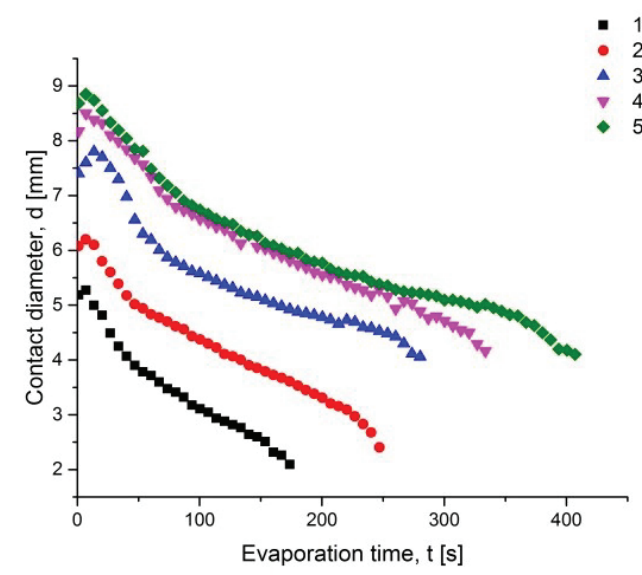

(b)

Fig. 1. Time dependences of the contact diameter of evaporating liquids: (a) distilled water; (b) binary liquid on aluminum surface heated up to $60^{\circ} \mathrm{C}$.

According to change in the contact diameter (Fig. 1 (a)) three evaporation modes of distilled water droplets on aluminum surface were detected: 
1 - an increase in the contact area;

2 - pinning of a droplet [16] (constant contact diameter);

3 - depinning of a droplet [16] (decrease in the contact diameter).

During evaporation of ethanol aqueous solution droplets, two evaporation modes were detected:

$1-$ an increase in the contact area;

2 - droplet depinning.

At the initial stage of evaporation an increase in the contact diameter (Fig. 1 (b)) and decrease in the contact angle (Fig. 2 (b)) occurs under the action of the mass forces.

Then, an intensive evaporation of alcohol occurs on the border of the three phases, and under the action of the surface forces a droplet shrinks, the contact area reduces, and the contact angle increases.

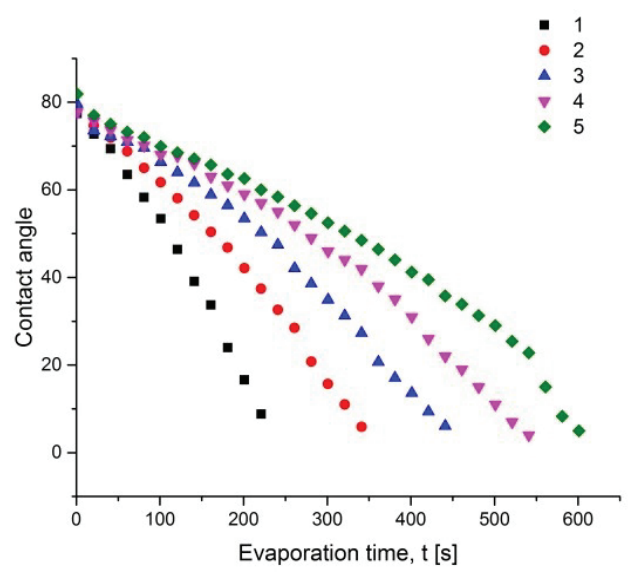

(a)

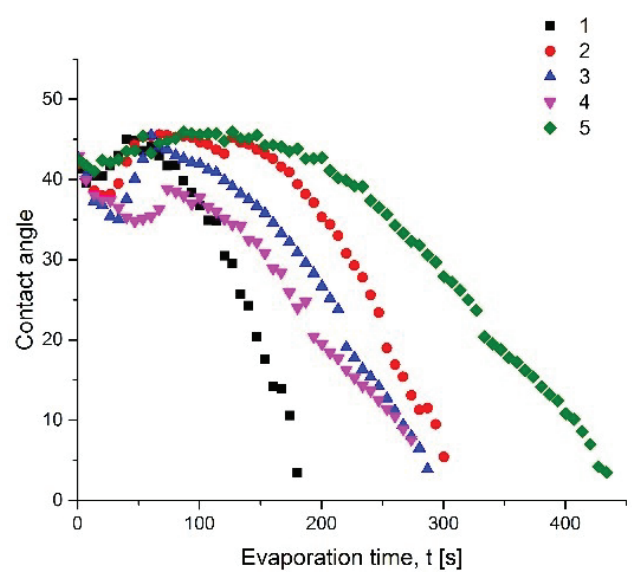

(b)

Fig. 2. Time dependences of the contact angle of evaporating droplets: (a) distilled water; (b) binary liquid on aluminum surface heated up to $60^{\circ} \mathrm{C}$.

The errors of image processing by different methods were estimated. The random error of Tangential 1 method does not exceed 3\%. The values of the contact angles in the initial period of time were $79.1^{\circ} \pm 2.1^{\circ}$ and $42.26^{\circ} \pm 0.57^{\circ}$ for water and binary liquid, respectively. They are within the error of the measuring system. It can be concluded that the volume of distilled water, and the binary liquid droplets on polished aluminum surface has no influence on the angle.

The change in volume of distilled water and binary liquid droplet is shown in Figure 3. 


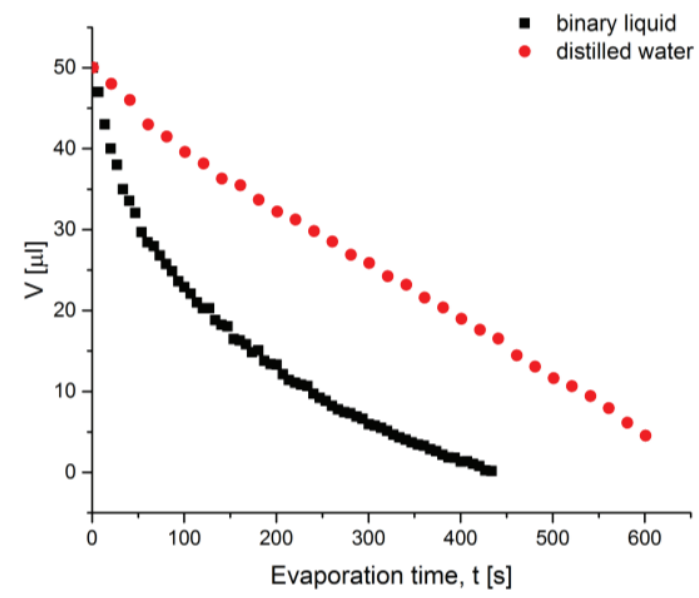

Fig. 3. Change in volume of distilled water and binary liquid droplet in time during evaporation.

It is worth noting that for water evaporation curve has linear nature; more than $70 \%$ of liquid from initial mass of droplet evaporates). For binary liquid in the initial time ((approximately the first 100 seconds) the evaporation rate (dynamics of droplet change) is maximal as ethanol evaporates mostly (heat of vaporization of alcohol is much less than for water). Over time, the alcohol concentration is reduced, and the evaporation rate becomes less intense, water evaporates.

The reported study was supported by the grant of President of Russian Federation for the government support of young Russian scientists (MK-6810.2016.8).

\section{References}

1. D. Zaitsev, D. Rodionov, O. Kabov, Tech. Phys. Lett., 35, 680 (2009)

2. D. Zaitsev, D. Kirichenko, O. Kabov, Tech. Phys. Lett., 41, 551 (2015)

3. D. Glushkov, J. Legros, P. Strizhak, A. Zakharevich, Fuel, 175, 105 (2016)

4. D. Glushkov, G. Kuznetsov, P. Strizhak, R. Volkov, Therm. Sci., 20, 131 (2016)

5. V. Lebedev, V. Lemanov, S. Misyura, V. Terekhov, Fluid Dyn., 28, 624 (1993)

6. V. Nakoryakov, S. Elistratov, S. Misyura, J. Eng. Phys. Thermophys., 20, 338 (2011)

7. M. Semenov, A. Manakov, E. Shitz, A. Stoporev, L. Altunina, L. Strelets, S. Misyura, V. Nakoryakov, J. Therm. Anal. Calorim., 119, 757 (2015)

8. I. Shanenkov, A. Sivkov, A. Pak, Y. Kolganova, Adv. Mat. Res., 1040, 813 (2014)

9. I. Shanenkov, A. Pak, A. Sivkov, Y. Shanenkova, MATEC Web of Conferences, 19 (2014)

10. G. Kuznetsov, N. Kurilenko, V. Maksimov, G. Mamontov, T. Nagornova, J. Eng. Phys. Thermophys., 86, 519 (2013)

11. O. Vysokomornaya, G. Kuznetsov, P. Strizhak, Fire Safety J., 70, 61 (2014)

12. G. Kuznetsov, D. Feoktistov, E. Orlova, Thermophys. Aeromech, 23, 17 (2016)

13. I. Afanasyev, E. Orlova, D. Feoktistov, EPJ Web of Conferences, 82, 01054 (2015)

14. G. Kuznetsov, D. Feoktistov, E. Orlova, J. Eng. Phys. Thermophys., 89, 317 (2016)

15. A. Semenov, D. Feoktistov, D. Zaitsev, G. Kuznetsov, O. Kabov Thermophys. Aeromech., 22, 771 (2015)

16. G. Kuznetsov, A. Zakharevich, N. Bel'kov, Chem. Pet. Eng., 50, 1 (2014)

17. K. Batischeva, E. Orlova, D. Feoktistov, MATEC Web of Conferences, 19, 01001 (2014)

18. G.V. Kuznetsov, D.V. Feoktistov, E.G. Orlova, K.A. Batishcheva, Colloid J. 78, 335 (2016) 